\title{
Pugh matrix and aggregated by extent analysis using trapezoidal fuzzy number for assessing conceptual designs
}

\author{
Olayinka Olabanji ${ }^{a^{*}}$ and Khumbulani Mpofu ${ }^{a}$
}

${ }^{a}$ Tshwane University of Technology Pretoria West South Africa, South Africa

\begin{tabular}{l} 
C H R O N I C L E \\
\hline Article history: \\
Received May 7, 2019 \\
Received in revised format: \\
August 25, 2019 \\
Accepted August 25, 2019 \\
Available online \\
August 25, 2019 \\
\hline Keywords: \\
Conceptual design \\
Multicriteria Decision-making \\
Fuzzified Pugh Matrix \\
Synthetic Extent Evaluation \\
Trapezoidal fuzzy number
\end{tabular}

\section{Introduction}

Decision making in engineering design towards selection of optimal design of a product or equipment still remains a major concern for manufacturers because they are usually interested in versatile designs that can be easily fabricated and gain market acceptance with a prolonged design life cycle before phasing out (Renzi et al., 2017; Olabanji, 2018). However, these designs cannot be totally achieved from the desk of conceptual designer alone but rather from collaboration with design experts' and decision-making team on conceptual design. An excellent strategy to achieve optimal conceptual design is usually to identify the design requirements from the users or market demand and also from the manufacturing point of view (Sa'Ed \& Al-Harris, 2014). The identified requirements are matched with design features, and various sub-features that can be used to characterize the design as described by the decision-making process in engineering design (Fig. 1). In actual fact, having an allencompassing design that satisfies all design requirements or features is a goal that seems not achievable because of the dynamic nature of the market that is swamped with diverse design due to

\footnotetext{
* Corresponding author.

E-mail address: obayinclox@gmail.com (O. Olabanji)

(C) 2020 by the authors; licensee Growing Science, Canada doi: $10.5267 /$ j.dsl.2019.9.001
} 
customers' requirements (Olabanji \& Mpofu, 2014; Renzi et al., 2015; Toh \& Miller, 2015). Given this, the design process usually involves the development of different design concepts based on functional requirements and design features. Hereafter, the decision-making team will collect the design concepts in order to select the optimal design concept (Okudan \& Shirwaiker, 2006; Akay et al., 2011; Aikhuele, 2017). Decision making in the conceptual phase of engineering design usually involves an evaluation of the design alternatives based on the identified and grouped design features and subfeatures respectively (Green \& Mamtani, 2004; Renzi et al., 2015). Two tasks that are usually done by design experts and decision-makers are assigning weights to the relative importance of the design features in the optimal design and assigning weights to the sub-features in order to ascertain and quantify their contributions to the performance of the design features (Girod et al., 2003; Arjun Raj \& Vinodh, 2016; Chakraborty et al., 2017). Design expert decision for establishing weight of design features in optimal design has been a long-term source of information for creating comparison among design features and sub-features when trying to select an optimal design from a set of alternative design concepts (Derelöv, 2009; Hambali et al., 2009; Hambali et al., 2011). However, there is a need to establish an objective process for determining these weights in order to reduce further or eliminate the risk of subjective or bias judgment in the decision process. Further, there is a need to introduce a systematic approach to the computational process in determining the optimal design concept from the alternatives.

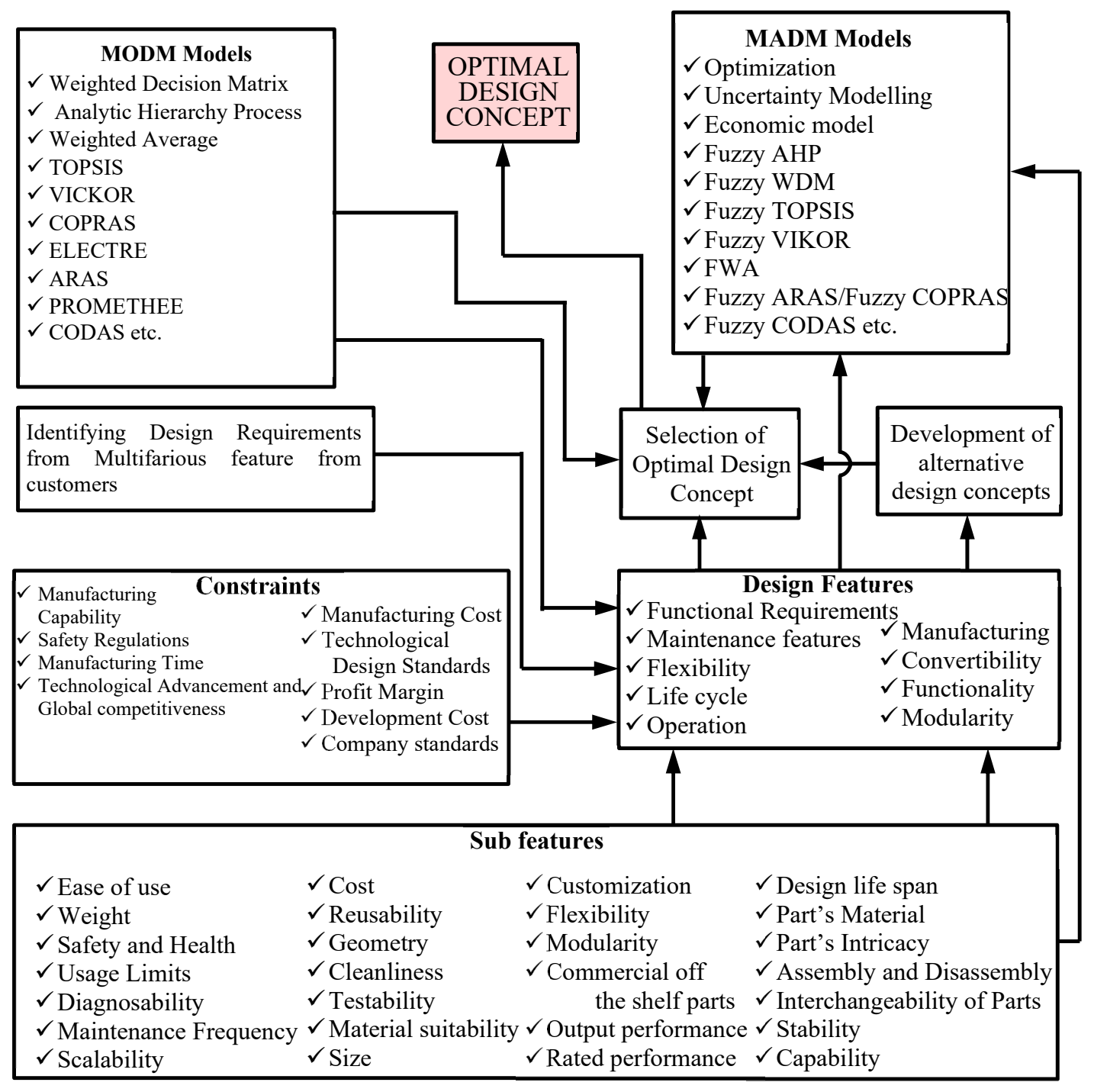

Fig. 1. Decision Making Process in Engineering Design 
Multicriteria Decision Making Analysis (MDMA) has been applied in different field of science, engineering and management to address the problems of decision making in order to select an optimal alternative that will suit the decision-makers (Saridakis \& Dentsoras, 2008; Baležentis \& Baležentis, 2014). MDMA can be classified into two aspects, namely; Multi-Objective Decision Making (MODM) and Multi-Attribute Decision Making (MADM). The MODM models are employed to make a decision when there are fewer criteria to be considered for evaluation. In situations like this, the decision matrix is developed for the alternatives with minimal consideration on the weights and dimensions of the criteria. The MADM models are employed to solve the problem of decision making in situations where the effects of the criteria on the optimal alternative is of importance, and there are sub-criteria allotted to the criteria of evaluation (Okudan \& Tauhid, 2008). In order to avoid bias in apportioning values to criteria of different dimensions, the fuzzy set theory is used to assign values to the linguistic terms used in ranking and rating the alternatives and criteria, respectively. In recent times, hybridizing MADM models to solve the problem of decision making has emerged as it provides an optimized decisionmaking process. Hybridized MADM models have been applied in different fields depending on the goal of the decision-makers and the importance attached to the decision-making process (Alarcin et al., 2014; Balin et al., 2016). However, the application of hybridized MADM to decision making at the conceptual stage of engineering design still requires attention. Although the Hybridized models provide an efficient and systematic procedure for selecting optimal alternative because they harness the computational advantage of two MADM models, but they pose a challenge of computational complexity. The complexity can be solved by converting the computational process into algorithms which can be developed into a program as a decision support tool.

This article proposes that, in order to have optimal decision-making at the conceptual stage of engineering design, it can be modelled as a multicriteria decision-making model. The design requirements are matched into design features and the design features are further divided into various sub-features. The optimal design concept is determined from Fuzzified Pugh Matrices (FPM) using all the design alternatives as a basis. The cumulative performance of the design alternatives is estimated using the weights of design features and sub-features that are obtained from fuzzified pairwise comparison matrices of Fuzzy Analytic Hierarchy Process (FAHP). Due to multifarious dimensions and units of the design features and sub-features and the aim of appropriately quantifying the imprecise information about the design alternatives, Trapezoidal Fuzzy Numbers (TrFN) are used to represent the linguistic terms for rating and ranking the design features and alternatives respectively. The cumulative TrFN of the design alternatives from the Pugh matrices are used to develop a pairwise comparison matrix from which the actual performance of the design alternatives is obtained using Fuzzy Synthetic Evaluation (FSE). In order to defuzzify and rank the TrFN of the FSE, it was reduced to a Triangular Fuzzy Number (TFN) then the degree of possibility that a design concept is better than the other is obtained from the orthocenter of three centroids of the plane figure under each $\mathrm{TrFN}$.

\section{Methodology}

In order to simplify the analysis, consider a framework for the developed MADM model as presented in Fig 2. Pairwise comparison matrices are needed for the sub-features and design features. The Fuzzy Synthetic Extent (FSE) of these comparison matrices are computed and used as weights of the design features, and sub-features in order to determine the cumulative TrFN for each design alternative from the Pugh matrices. The linguistic terms of the TrFN for the pairwise comparison matrices and Pugh matrices are different, and as such, they are described in Table 1. The cumulative TrFN from the Pugh matrices are also harnessed to create a pairwise comparison matrix for the design alternatives. FSEs are obtained for the design alternatives from the pairwise comparison matrices in the form of TrFN, which are further reduced to centroids of orthocenter in the form of Triangular Fuzzy Numbers (TFNs). The degree of possibility of is obtained from these orthocenters which provide weights for each of the alternative design concepts. 


\section{Table 1}

TrFNs and Linguistic terms for the Pairwise Comparison Matrices and Pugh Matrices

\begin{tabular}{|c|c|c|c|c|c|}
\hline \multicolumn{3}{|c|}{ Pairwise Comparison Matrices } & \multicolumn{3}{|c|}{ Pugh Matrices } \\
\hline $\begin{array}{l}\text { Linguistic Terms for Raking of } \\
\text { Relative Significance of design } \\
\text { features and sub-features in the } \\
\text { Optimal Design }\end{array}$ & $\begin{array}{l}\text { Trapezoidal Fuzzy Scale } \\
\text { Membership Function }\end{array}$ & $\begin{array}{l}\text { Crisp Value } \\
\text { of Ranking }\end{array}$ & $\begin{array}{l}\text { Linguistic Terms for } \\
\text { rating Design } \\
\text { concepts considering } \\
\text { the sub-features }\end{array}$ & $\begin{array}{l}\text { Trapezoidal Fuzzy Scale } \\
\text { Membership Function }\end{array}$ & $\begin{array}{c}\text { Crisp } \\
\text { Value of } \\
\text { Rating }\end{array}$ \\
\hline Equally Important & 11 & 1 & Much Better & $\begin{array}{llll}13 / 4 & 15 / 4 & 17 / 4 & 19 / 4\end{array}$ & $\mathrm{~S}++$ \\
\hline Weakly Important & $\begin{array}{llll}1 & 3 / 2 & 2 & 5 / 2\end{array}$ & 2 & Better & $5 / 2 \quad 3$ & $\mathrm{~S}+$ \\
\hline Essentially Important & $\begin{array}{llll}7 / 4 & 9 / 4 & 11 / 4 & 13 / 4\end{array}$ & 3 & Same & $\begin{array}{llll}1 & 1 & 1 & 1\end{array}$ & $\mathrm{~S}$ \\
\hline Highly Important & $\begin{array}{llll}5 / 2 & 3 & 7 / 2 & 4\end{array}$ & 4 & Worse & $\begin{array}{llll}7 / 4 & 9 / 4 & 11 / 4 & 13 / 4\end{array}$ & S- \\
\hline Very highly Important & $\begin{array}{llll}13 / 4 & 15 / 4 & 17 / 4 & 19 / 4\end{array}$ & 5 & Much Worse & $\begin{array}{llll}1 & 3 / 2 & 2 & 5 / 2\end{array}$ & S-- \\
\hline
\end{tabular}

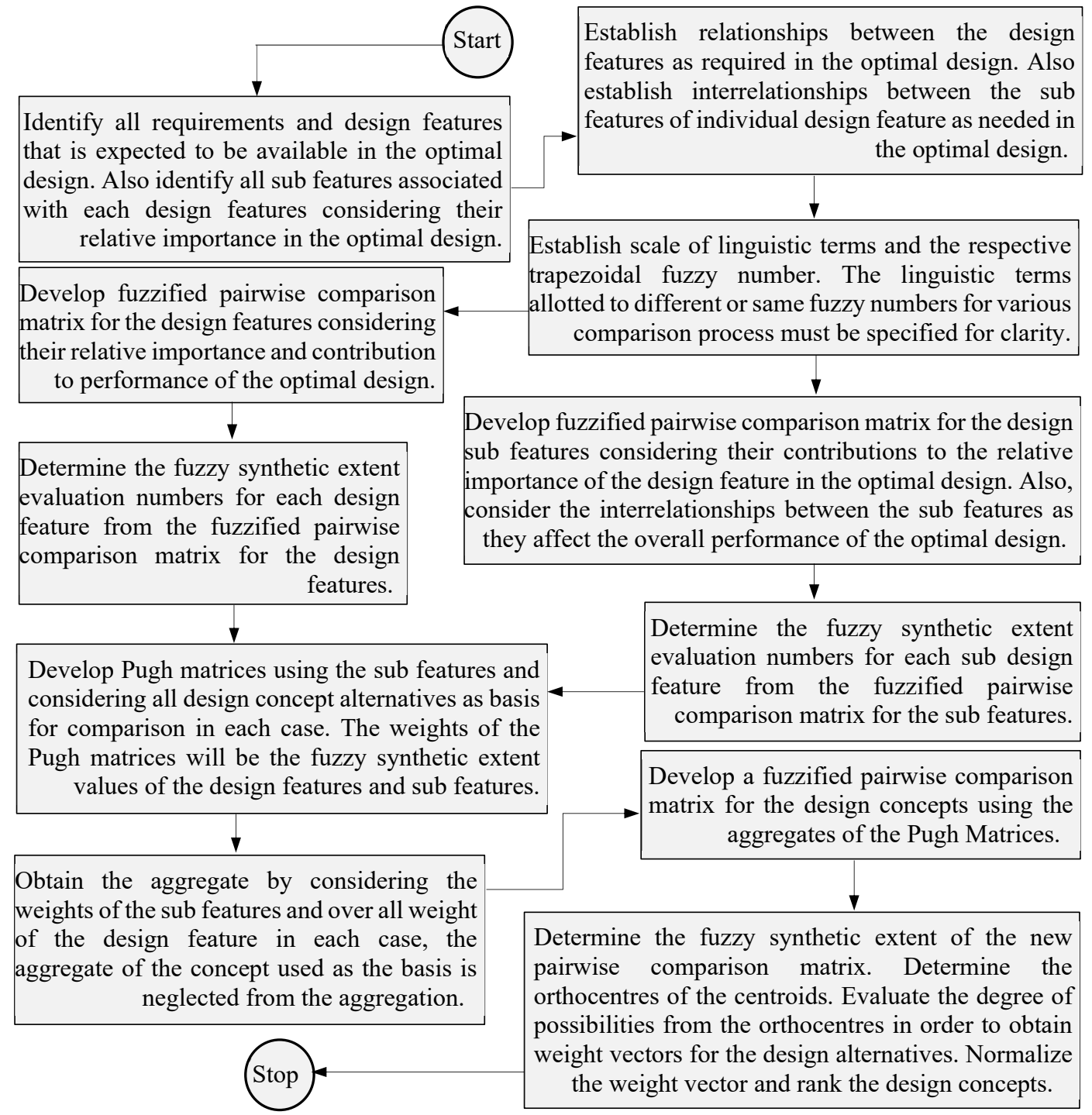

Fig. 2. Framework for the Fuzzified Pugh Matrix Model

In order to develop pairwise comparison matrices for the sub-features and design features, it is necessary to assign $\operatorname{TrFN}\left(M_{x}\right)$ to the elements of the matrices using linguistic terms. Consider $m$ number of design alternatives $\left(D_{A m}\right)$ from which an optimal design will be chosen using $k$ number of design features $\left(D_{F k}\right)$ that are characterized by $n$ number of sub-features $\left(S_{F n}\right)$. The membership function ' $\mu_{m}(x)^{\prime}$ of the trapezoidal fuzzy number $M=\{p, q, r, s\}$ can be expressed by Eq. (1), as presented in Fig. 3; (Singh, 2015; Velu et al., 2017), 


$$
\mu_{m}(x)= \begin{cases}\frac{x-p}{q-p} & x \in[p, q] \\ 1 & x \in[q, r] \\ \frac{s-x}{s-r} & x \in[r, s] \\ 0 & \text { Otherwise }\end{cases}
$$

where $p \leq q \leq r \leq s$ with orthocentres of three centroids $\left(G_{1}, G_{2}, G_{3}\right)$ obtained from equations 2,3 and 4 respectively as presented in Fig. 3. Judgement matrices of the form $\tilde{Q}=\left\{\tilde{q}_{g i}^{j}\right\}$ can be developed for pairwise comparison matrices of the design features and sub-features. Where $j$ and $i$ represent columns and rows, respectively. In essence, the judgement matrix for the sub-features can be expressed in equation 5. Also, the comparison matrix for the design features can be described as presented in equation 6 (Somsuk \& Simcharoen, 2011; Thorani et al., 2012; Zamani et al., 2014).

$$
\begin{aligned}
& G_{1}=\frac{p+2 q}{3}=a \\
& G_{2}=\frac{q+r}{2}=b \\
& G_{3}=\frac{2 r+s}{3}=c
\end{aligned}
$$

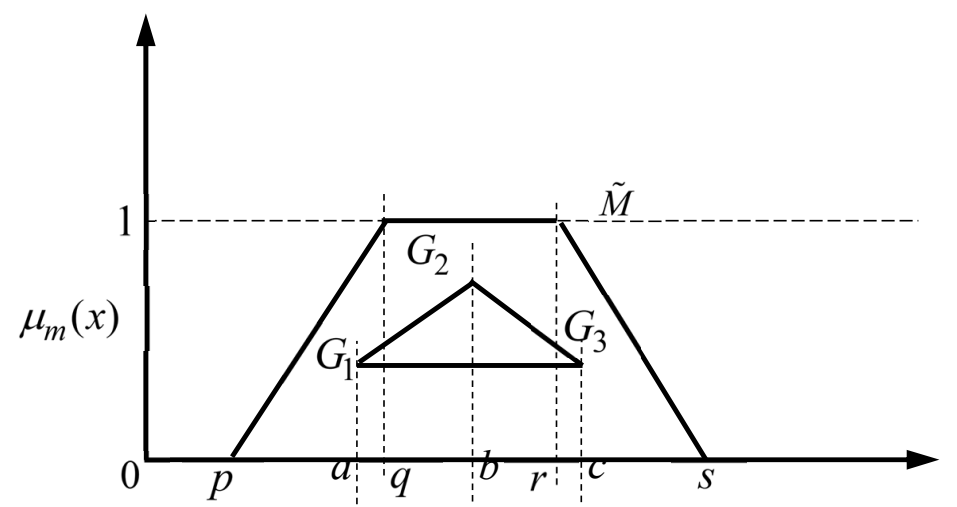

Fig. 3. Representation of the TrFN with three centroids orthocentres

$$
\begin{gathered}
\left.\tilde{S}_{F_{n}}\right|_{i}=\left(\begin{array}{ccc}
\tilde{s}_{f 1}^{1} & \tilde{s}_{f 1}^{2} & \ldots \ldots \ldots . . \tilde{s}_{f 1}^{j} \\
\tilde{s}_{f 2}^{1} & \tilde{s}_{f 2}^{2} & \ldots \ldots \ldots . . \tilde{s}_{f 2}^{j} \\
\vdots & \vdots & \vdots \\
\tilde{s}_{f i}^{1} & \tilde{s}_{f i}^{1} & \ldots \ldots \ldots . . \tilde{s}_{f i}^{j}
\end{array}\right) \\
\tilde{D}_{F_{k}}=\left(\begin{array}{ccc}
\tilde{d}_{f 1}^{1} & \tilde{d}_{f 1}^{2} & \ldots \ldots \ldots . . \tilde{d}_{f 1}^{j} \\
\tilde{d}_{f 2}^{1} & \tilde{d}_{f 2}^{2} & \ldots \ldots \ldots . . . \tilde{d}_{f 2}^{j} \\
\vdots & \vdots & \vdots \\
\tilde{d}_{f i}^{1} & \tilde{d}_{f i}^{1} & \ldots \ldots \ldots . . \tilde{d}_{f i}^{j}
\end{array}\right)
\end{gathered}
$$

The FSEs for sub features' and design features pairwise comparison matrices can be obtained from Eq. (7) and Eq. (8), respectively. These FSEs represents the weights of the sub-features and design features 
which can be represented as $S_{w}^{f_{n}}$ and $D_{w}^{f_{i}}$ respectively (Nieto-Morote \& Ruz-Vila, 2011; Tian \& Yan, 2013).

$$
\begin{aligned}
& \left.S_{w}^{f_{n}}\right|_{i}=\left[F_{s e}\right]_{\tilde{S}_{F_{n}}}=\sum_{j=1}^{s} s_{f i}^{j} \otimes\left[\sum_{i=1}^{k} \sum_{j=1}^{s} s_{f i}^{j}\right]^{-1} \\
& D_{w}^{f_{k}}=\left[F_{s e}\right]_{\tilde{D}_{f}}=\sum_{j=1}^{s} d_{f i}^{j} \otimes\left[\sum_{i=1}^{k} \sum_{j=1}^{s} d_{f i}^{j}\right]^{-1}
\end{aligned}
$$

The Pugh matrix is designed and formulated using all the design alternatives as a basis. This implies that there is $m$ number of Pugh matrix since there is $M$ number of design alternatives. The matrix can be expressed, as presented in equation 9. It is worthwhile to know that equation 9 represents when one of the design concepts is taken as baseline. Hence, for $m$ number of design concepts, there will be $m$ number of equation 9 (Muller, 2009, Muller et al., 2011).

$$
\begin{aligned}
& \begin{array}{llllll}
\tilde{S}_{w(1)}^{f 1} & \tilde{P}_{g 1}^{(1) 1} & \tilde{P}_{g 1}^{(1) 2} & \ldots & \ldots & \tilde{P}_{g 1}^{(1) j}
\end{array} \\
& \begin{array}{lllllll}
\tilde{D}_{w}^{f(1)} & \tilde{S}_{w(1)}^{f 2} & \tilde{P}_{g 2}^{*}(1) 1 & \tilde{P}_{g 2}^{(1) 2} & \ldots & \ldots & \tilde{P}_{g 2}^{(1) j}
\end{array}
\end{aligned}
$$

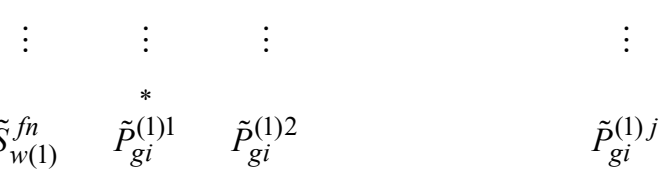

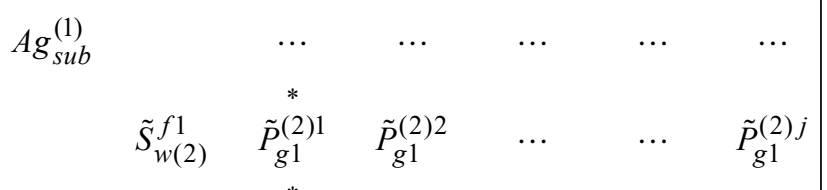

$$
\begin{aligned}
& \begin{array}{lllllll}
\tilde{D}_{w}^{f(2)} & \tilde{S}_{w(2)}^{f 2} & \tilde{P}_{g 2}^{*}(2) 1 & \tilde{P}_{g 2}^{(2) 2} & \ldots & \ldots & \tilde{P}_{g 2}^{(2) j}
\end{array}
\end{aligned}
$$

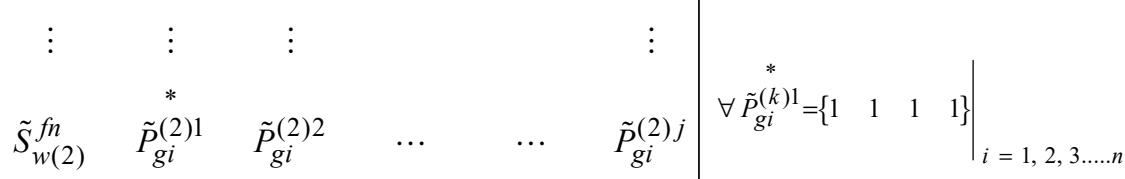

$$
\begin{aligned}
& \begin{array}{llllll}
A g_{\text {sub }}^{(2)} & \ldots & \ldots & \ldots & \ldots & \ldots
\end{array} \\
& \begin{array}{llllll}
\vdots & \vdots & \vdots & \vdots & \vdots & \vdots
\end{array} \\
& \begin{array}{llllll}
\tilde{S}_{w(k)}^{f 1} & \tilde{P}_{g 1}^{(k) 1} & \tilde{P}_{g 1}^{(k) 2} & \ldots & \tilde{P}_{g 1}^{(k) j}
\end{array} \\
& \begin{array}{lllllll}
\tilde{D}_{w}^{f(k)} & \tilde{S}_{w(k)}^{f 2} & \tilde{P}_{g 2}^{(k) 1} & \tilde{P}_{g 2}^{(k) 2} & \ldots & \tilde{P}_{g 2}^{(k) j}
\end{array} \\
& \begin{array}{llll}
\vdots & \vdots & \vdots & \vdots
\end{array} \\
& \begin{array}{llllll}
\tilde{S}_{w(k)}^{f n} & \tilde{P}_{g i}^{(k) 1} & \tilde{P}_{g i}^{(k) 2} & \ldots & \ldots & \tilde{P}_{g i}^{(k) j}
\end{array} \\
& \begin{array}{llllll}
A g_{\text {sub }}^{(k)} & \ldots & \ldots & \ldots & \ldots & \ldots
\end{array}
\end{aligned}
$$

Also, considering Eq. (9), for the design concept considered as a baseline, its sub aggregate takes the value of "same" (see Table 1). This implies that; 


$$
\left.A g_{\text {sub }}^{(k)}\right|_{i} ^{j}=\left.\left[\begin{array}{llll}
1 & 1 & 1 & 1
\end{array}\right]\right|_{i=j=1}
$$

Further, the sub aggregate of the comparison for a design feature can be obtained for the design concepts that are not considered as baseline. These aggregates can be derived from;

$$
A g_{s u b}^{(k)}=\tilde{D}_{w}^{f(k)} \times \sum_{i=1}^{i=n}\left[\tilde{S}_{w(k)}^{f n} * \tilde{P}_{g i}^{(k) j}\right]
$$

The overall aggregate for the design concepts that are not considered as a baseline $\left(D_{A g}\right)$ in a particular matrix can be obtained from the summation of the sub aggregates as presented in Eq. (12).

$$
\tilde{D}_{A g}=\left.\sum_{k=1}^{k=k} A g_{s u b}^{(k)}\right|_{j=1,2, \ldots \ldots . m}
$$

The overall aggregates obtained from the Pugh matrices are used to formulate a pairwise comparison matrix for the design concepts. The pairwise comparison matrix is o the form;

$$
\begin{aligned}
& \left.\left.\left.\tilde{A} g_{\text {sub }}^{(k)}\right|_{1} ^{1} \quad \tilde{D}_{A g}\right|_{1} ^{2} \quad \ldots \quad \ldots \quad \tilde{D}_{A g}\right|_{1} ^{m} \\
& \left.\left.\left.\tilde{D}_{A g}\right|_{2} ^{1} \quad \tilde{A} g_{s u b}^{(k)}\right|_{2} ^{2} \quad \ldots \quad \ldots \quad \tilde{D}_{A g}\right|_{2} ^{m} \\
& \begin{array}{llll}
\vdots & \vdots & \ddots & \vdots
\end{array} ; m=\text { number of design concept } \\
& \vdots \quad \vdots \quad \ddots \quad \\
& \left.\left.\left.\tilde{D}_{A g}\right|_{m} ^{1} \quad \tilde{D}_{A g}\right|_{m} ^{2} \quad \ldots \quad \quad \ldots \quad \tilde{A} g_{s u b}^{(k)}\right|_{m} ^{m}
\end{aligned}
$$

Fuzzy Synthetic Evaluation values in the form of TrFN are also obtained for the design alternatives using Eq. (14).

$$
\tilde{D}_{A m}=\left[F_{s e}\right]_{\tilde{D}_{A m}}=\left.\sum_{j=1}^{m} \tilde{D}_{A g}\right|_{m} ^{m} \otimes\left[\left.\sum_{i=1}^{m} \sum_{j=1}^{m} \tilde{D}_{A g}\right|_{m} ^{m}\right]^{-1}
$$

Eq. (2) to Eq. (4) can be used to determine the orthocentres of the centroids of TrFNs for the FSE obtained in equation 14 (see Fig. 3). Consider the membership function of a trapezoidal fuzzy number $M=\{p, q, r, s\}$, applying Eq. (2) to Eq. (4), the three orthocentres of the centroids can be obtained in the form of TFN having a membership function ' $\mu_{g}(y)$ ' for $G=\{a, b, c\}$. This will represent the TFN value of the $m t h$ design concept. The minimum degree of possibilities $\left(P_{i} \geq P_{j}\right)$ can be obtained for each design alternative from Eq. (15) and Eq. (16) in order to obtain their priority values (Somsuk \& Simcharoen, 2011). The priority values will represent weight vectors that will be normalized from Eq. (17) before ranking the design concepts. 


$$
V\left(P_{i} \geq P_{m}\right)=\text { heights }\left(P_{m} \cap P_{i}\right)= \begin{cases}1 & \text { if } b_{i} \geq b_{m} \\ 0 & \text { if } a_{m} \geq c_{i} \\ \frac{a_{m}-c_{i}}{\left(b_{i}-c_{i}\right)-\left(b_{m}-a_{m}\right)} & \text { otherwise }\end{cases}
$$

$\min V\left(P \geq P_{1}, P_{2} \ldots \ldots \ldots P_{i}\right)$

$p_{i}=\frac{P_{i}^{\prime}}{\sum_{i=1}^{m} P_{i}^{\prime}}$

\section{Application}

In order to verify the developed model, it was applied to decision making on four conceptual designs of liquid spraying machine. A decision tree is developed showing all the design features, sub-features and design concepts as presented in Fig. 4. Firstly, the fuzzified pairwise comparison matrix was developed for all the sub-features under each of the design features. The FSEs of the pairwise comparison matrices for the sub-features and design features were estimated from equations 7 and 8 , respectively. An example of the fuzzified pairwise comparison matrix for maintainability is presented in Table 2. It is worthwhile to know that since there are eight design features, then eight matrices will be developed for all the design feature. In order to reduce the content of this article, only the FSEs of these matrices will be presented, as shown in Table 3 to Table 10. These FSEs are adopted as the weights of the sub-features and design features. The weights of the sub-features are presumed to be a function of their relative contributions to the performance of the design features, while the weights of the design features are expected to be their relative importance in the optimal design. Further, Pugh matrices are developed using the four design concepts as a baseline. An example of the Pugh matrices using concept one as a basis is presented in Table 11. These matrices were aggregated using the weights of the design feature and sub-features by applying equations 10 and 11 . The aggregate TrFNs from the Pugh matrices using all the design concepts as a basis is also presented in Table 11. These aggregates are then applied to develop a pairwise comparison matrix for the design concepts as presented in Table 12.

Table 2

Fuzzy Synthetic Evaluation Matrix for Sub features of Maintainability

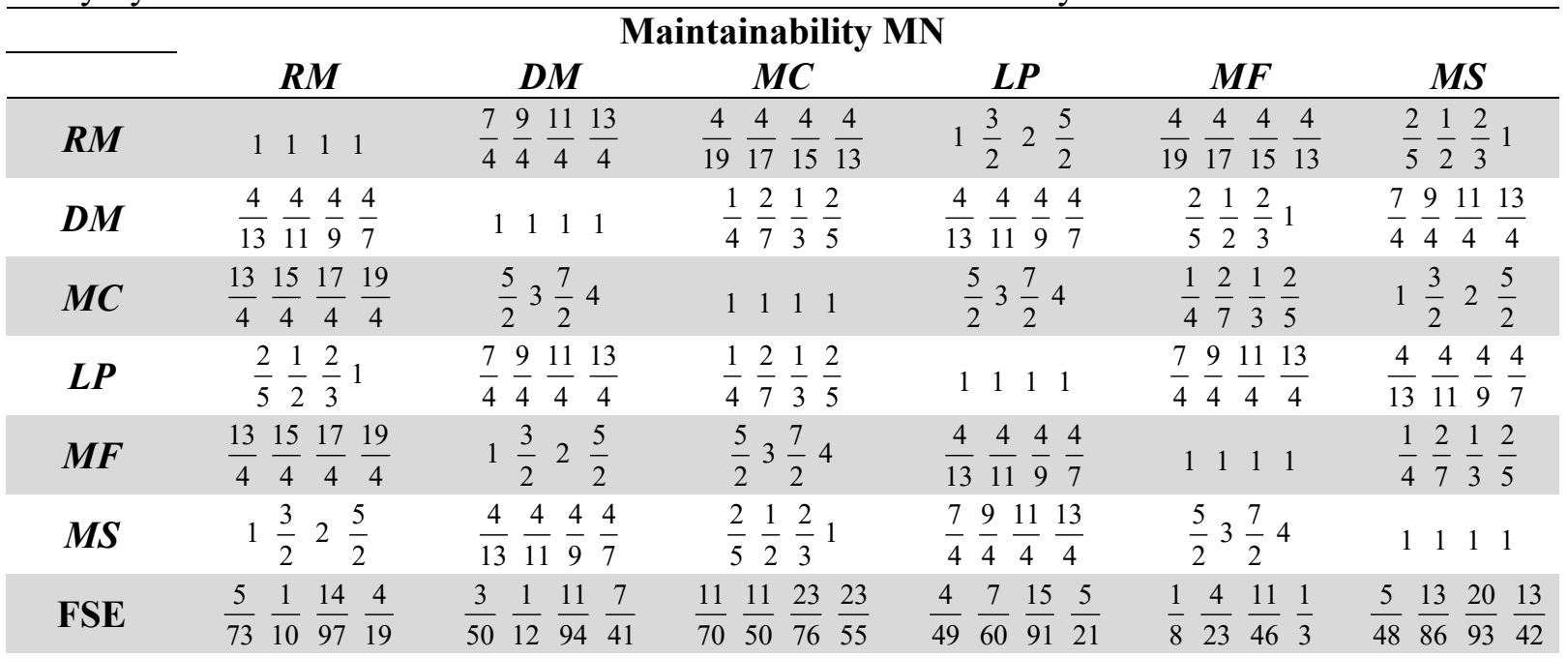




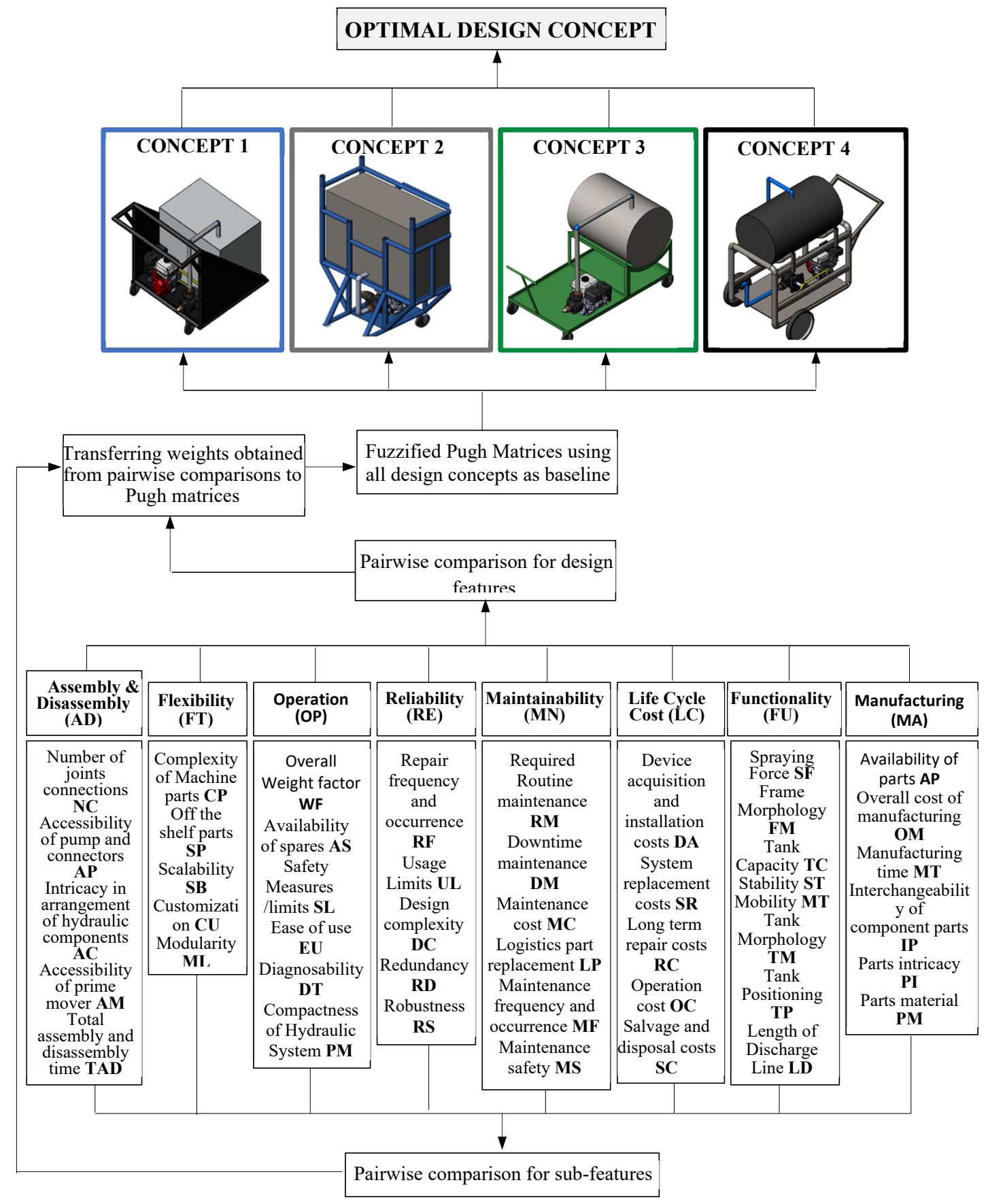

Fig. 4. Decision Tree for Optimal Design of Liquid Spraying Machine

Table 3

Fuzzy Synthetic Evaluation Matrix for Sub features of Reliability

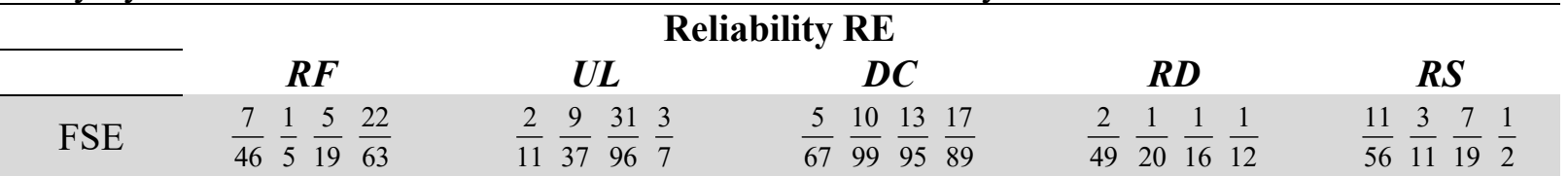


Table 4

Fuzzy Synthetic Evaluation Matrix for Sub features of Flexibility

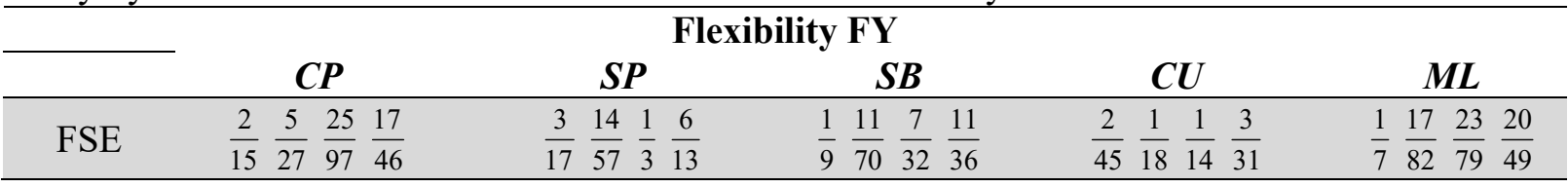

Table 5

Fuzzy Synthetic Evaluation Matrix for Sub features of Operation

\section{Operation OP}

$\begin{array}{llllll}W F & A S & S L & E U & D T & P M\end{array}$

FSE $\quad \frac{9}{98} \frac{9}{70} \frac{13}{73} \frac{1}{4} \quad \frac{1}{10} \frac{6}{41} \frac{6}{29} \frac{12}{41} \quad \frac{7}{74} \frac{1}{7} \frac{19}{92} \frac{19}{62} \quad \frac{9}{47} \frac{17}{63} \frac{22}{59} \frac{15}{29} \quad \frac{3}{49} \frac{3}{35} \frac{5}{41} \frac{2}{11} \quad \frac{3}{62} \frac{4}{57} \frac{8}{79} \frac{12}{79}$

\section{Table 6}

Fuzzy Synthetic Evaluation Matrix for Sub features of Manufacturing

\begin{tabular}{ccccccccccc}
\hline & \multicolumn{9}{c}{ Manufacturing MA } & \multicolumn{1}{c}{} \\
\hline & $\boldsymbol{A P}$ & $\boldsymbol{O M}$ & $\boldsymbol{M T}$ & $\boldsymbol{I P}$ & $\boldsymbol{P I}$ & $\boldsymbol{P M}$ \\
\hline FSE & $\frac{5}{63} \frac{5}{41} \frac{17}{95} \frac{6}{23}$ & $\frac{7}{39} \frac{21}{82} \frac{5}{14} \frac{1}{2}$ & $\frac{3}{52} \frac{7}{79} \frac{5}{38} \frac{12}{61}$ & $\frac{3}{64} \frac{4}{59} \frac{4}{41} \frac{9}{62}$ & $\frac{4}{97} \frac{1}{18} \frac{5}{63} \frac{9}{71}$ & $\frac{2}{11} \frac{1}{4} \frac{31}{90} \frac{11}{23}$ \\
\hline
\end{tabular}

Table 7

Fuzzy Synthetic Evaluation Matrix for Sub features of Assembly and Disassembly

\begin{tabular}{|c|c|c|c|c|c|}
\hline & & Assembl & Disassembly & & \\
\hline & $N C$ & $A P$ & $A C$ & $A M$ & $T A D$ \\
\hline FSE & $\frac{3}{71} \frac{1}{19} \frac{2}{29} \frac{7}{79}$ & $\frac{2}{21} \frac{7}{55} \frac{3}{17} \frac{11}{46}$ & $\frac{1}{9} \frac{14}{89} \quad \frac{7}{31} \frac{14}{45}$ & $\frac{5}{36} \frac{1}{5} \frac{2}{7} \frac{13}{34}$ & $\frac{4}{17} \quad \frac{27}{91} \quad \frac{4}{9} \quad \frac{7}{12}$ \\
\hline
\end{tabular}

Table 8

Fuzzy Synthetic Evaluation Matrix for Sub features of Life Cycle Cost

\begin{tabular}{lccccccc}
\hline \multicolumn{7}{c}{ DA } & \multicolumn{7}{c}{ Life Cycle Cost LC } \\
\hline FSE & $\frac{9}{58} \frac{20}{97} \frac{26}{95} \frac{10}{27}$ & $\frac{2}{35} \frac{7}{87} \frac{1}{9} \frac{2}{13}$ & $\frac{5}{47} \frac{10}{67} \frac{13}{63} \frac{15}{52}$ & $\frac{11}{48} \frac{14}{45} \frac{5}{12} \frac{5}{9}$ & $\frac{3}{34} \frac{11}{95} \frac{12}{79} \frac{16}{79}$ \\
\hline
\end{tabular}

Table 9

Fuzzy Synthetic Evaluation Matrix for Sub features of Functionality

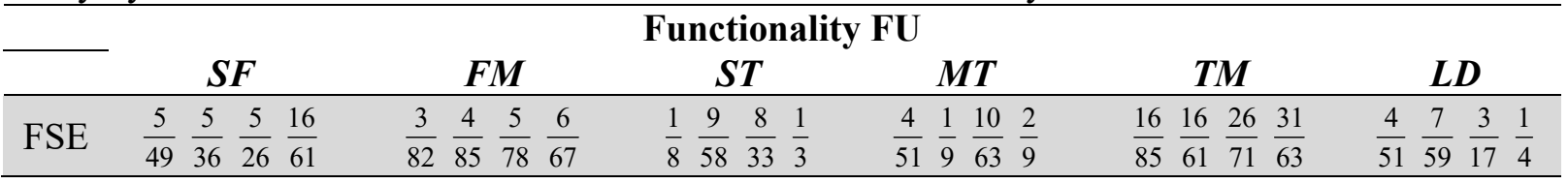

Table 10

Fuzzy Synthetic Evaluation Matrix for the Design Features

\section{Design Features}

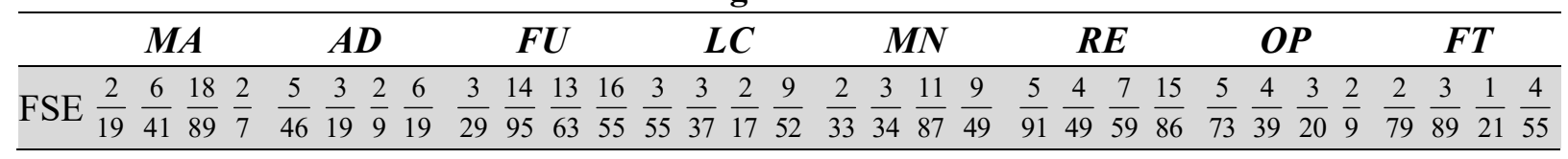


Table 11

Fuzzified Pugh Matrix using Design Concept one as a baseline

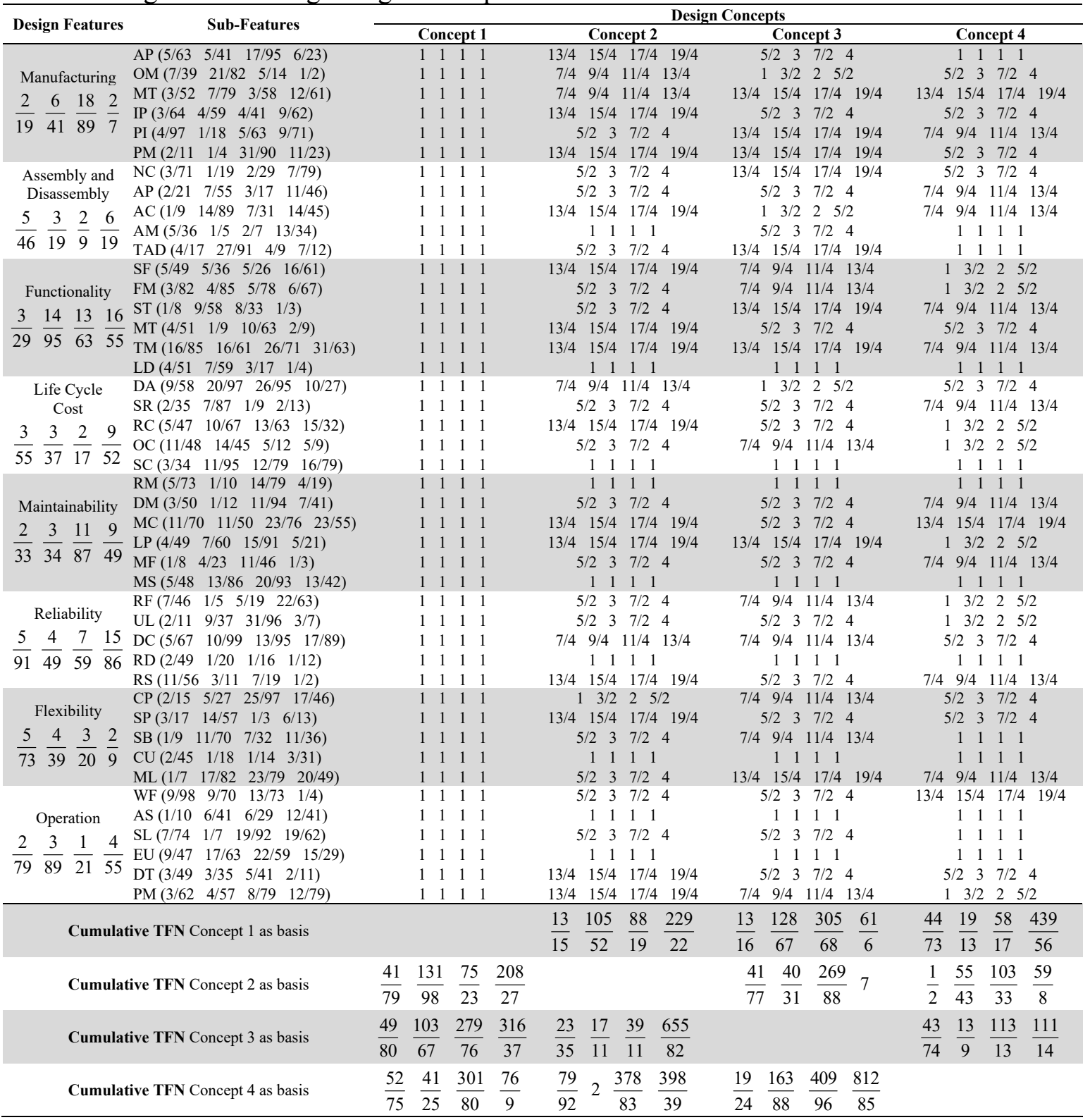

Table 12

FSE Aggregating the comparison and Ranking the Design Concepts

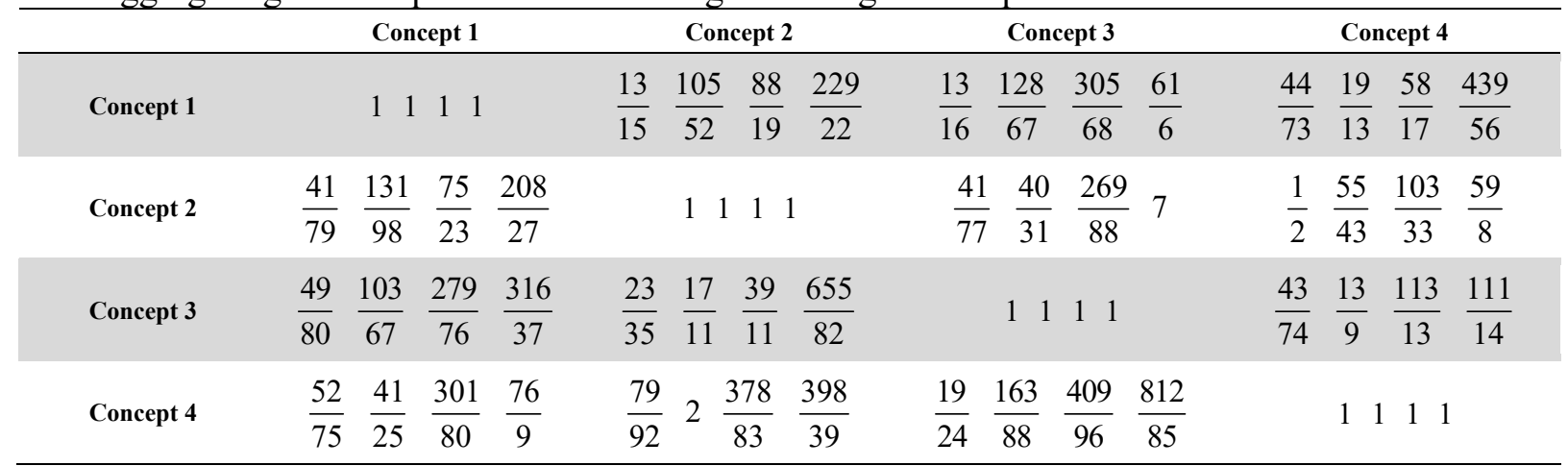




\section{Table 12}

FSE Aggregating the comparison and Ranking the Design Concepts (Continued)

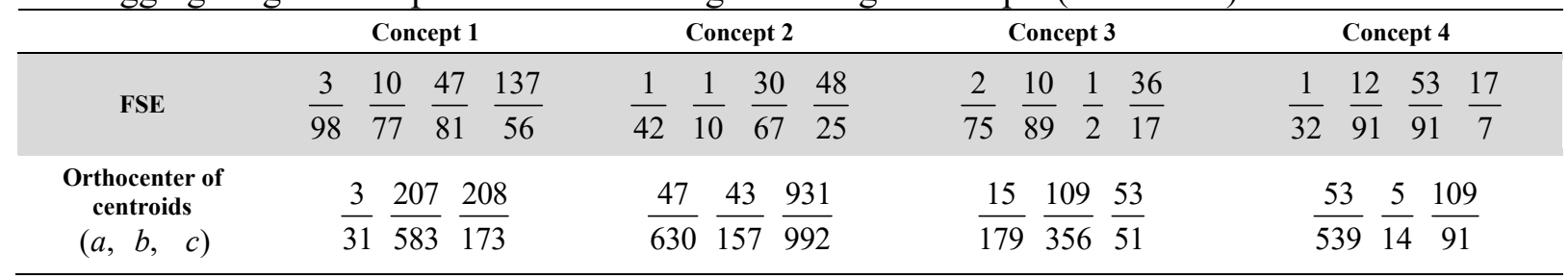

Fuzzy synthetic extent values are also obtained from the comparison matrix of the alternative design concepts in Table 15 in terms of TrFN, and the orthocenters of centroids of these values are derived by applying Eq. (2) to Eq. (4). Considering the orthocenters obtained in Table 15, the degree of possibility of $P_{i}=\left(a_{i}, b_{i}, c_{i}\right) \geq P_{n}=\left(a_{m}, b_{m}, c_{m}\right)$ can be expressed by applying Eq. (15) as follows;

$$
\begin{aligned}
& V\left(D_{A 1} \geq D_{A 2}\right)=1 \text {; Since } b_{1}>b_{2} \\
& V\left(D_{A 1} \geq D_{A 3}\right)=1 ; \text { Since } b_{1}>b_{3} \\
& V\left(D_{A 1} \geq D_{A 4}\right)=\frac{\left(\frac{53}{539}-\frac{208}{173}\right)}{\left(\frac{207}{583}-\frac{208}{173}\right)-\left(\frac{5}{14}-\frac{53}{539}\right)}=\frac{528}{531}
\end{aligned}
$$

Following the same manner, the degree of possibilities for all other design concepts can be obtained from Eq. (15). The results obtained for the analysis of minimum degree are as follows

$$
\begin{aligned}
& \min V\left(D_{A 1} \geq D_{A 2}, D_{A 3}, D_{A 4}\right)=\min V\left(1,1, \frac{528}{531}\right)=\frac{528}{531} \\
& \min V\left(D_{A 2} \geq D_{A 1}, D_{A 3}, D_{A 4}\right)=\min V\left(\frac{197}{216}, \frac{344}{357}, \frac{111}{122}\right)=\frac{111}{122} \\
& \min V\left(D_{A 3} \geq D_{A 1}, D_{A 2}, D_{A 4}\right)=\min V\left(\frac{617}{649}, 1, \frac{240}{253}\right)=\frac{240}{253} \\
& \min V\left(D_{A 4} \geq D_{A 1}, D_{A 2}, D_{A 3}\right)=\min V(1,1,1)=1
\end{aligned}
$$

In essence, the weight vector for the design concepts can be written as;

$$
\left[\begin{array}{l}
D_{A 1}(\text { Concept } 1)=\frac{528}{531} \\
D_{A 2}(\text { Concept } 2)=\frac{111}{122} \\
D_{A 3}(\text { Concept } 3)=\frac{240}{253} \\
D_{A 4}(\text { Concept } 4)=1
\end{array}\right]
$$

Normalizing the weight vector by applying Eq. (17) yields the overall weight for each of the design concepts alongside with their rankings (Eq. (26)). These weights are presented in Fig. 5 in order to see the performance of all the design concepts. 


$$
\left[\begin{array}{l}
D_{A 1}(\text { Concept } 1)=\frac{209}{823} \\
D_{A 2}(\text { Concept } 2)=\frac{67}{284} \\
D_{A 3}(\text { Concept } 3)=\frac{168}{683} \\
D_{A 4}(\text { Concept } 4)=\frac{251}{968}
\end{array}\right]\left[\begin{array}{l}
\text { Ranking } \\
-\Rightarrow 2^{\text {nd }} \\
-\Rightarrow 4^{\text {th }} \\
-\Rightarrow 3^{\text {rd }} \\
-\Rightarrow 1^{\text {st }}
\end{array}\right]
$$

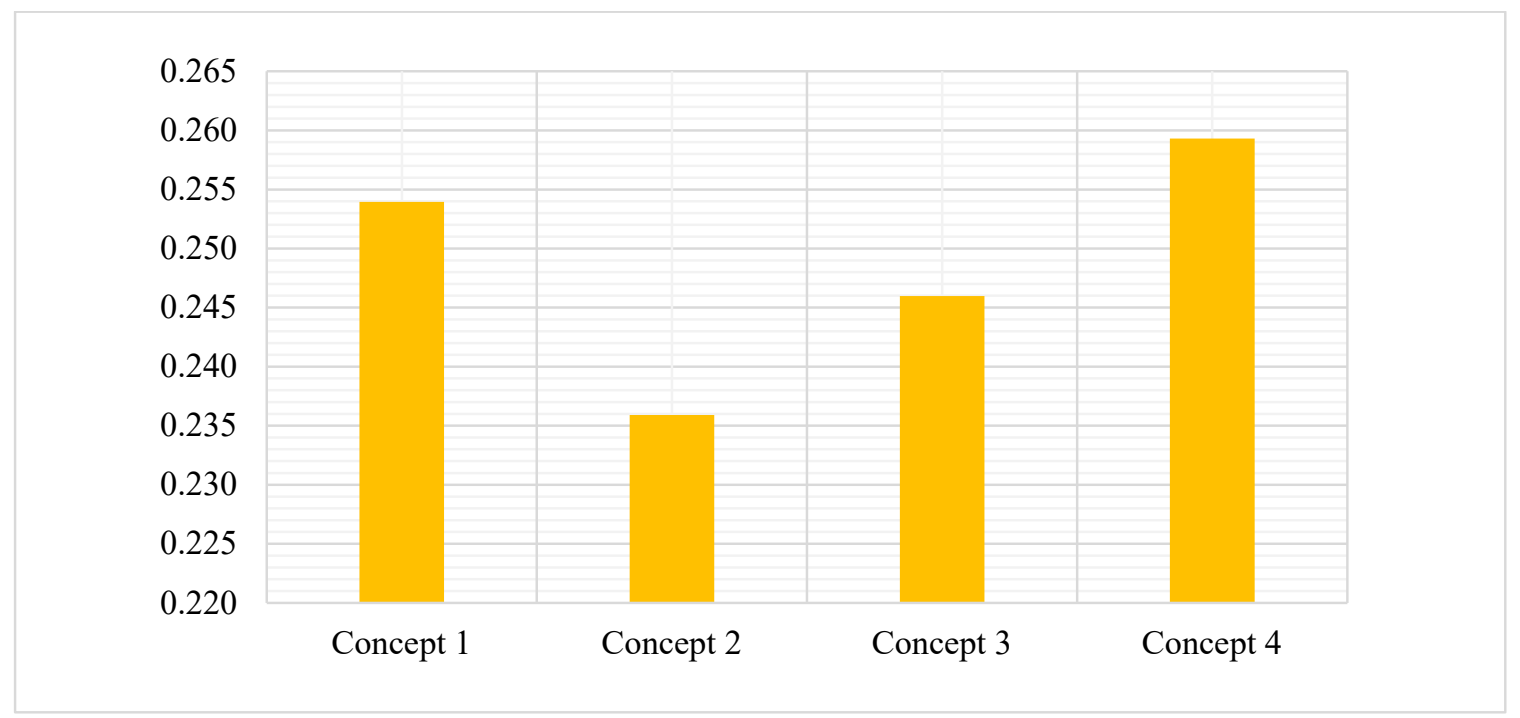

Fig. 5. Ranking of Design Concepts

\section{Conclusion}

Considering the results obtained from the decision process (Fig. 5), the developed model has been able to identify a design concept as the optimal design. Although the difference between the optimal design concept and the second design alternative is minimal, the trend in the difference of final weights of the design concepts shows that the decision process does not apportion values to the design concepts arbitrarily. This can be proven from the weights of concepts three and two because there is also a reasonable difference between the final weight of the optimal design concept to these two design concepts. The closeness in final weights of the design concepts can also be attributed to the involvement of the weights of design features and sub-features in determining the cumulative $\mathrm{TrFN}$ of the design concepts. The involvement of these weights tends to neutralize the effects of over scoring a concept.

Likewise, the idea of using all the design concepts as baselines also provide a case for all the design alternative to be compared among each other. Further, the usage of all the design alternative as baseline also provides computational integrity in terms of the final aggregates available for all the design concepts considering the weights of the design features and sub-features. Contrary to the conventional Pugh matrix evaluation, where the final values of the alternatives are direct cumulative of scores, the model presented in this article further compares this aggregate in order to eliminate the effect of over scoring a concept by bias through the use of FSEs for the pairwise comparison of the alternative design. Finally, the determination of the final weights of the design concepts from the degree of possibility further compares the design concepts rather than defuzzifying the TrFNs of the design concepts. 
In essence, modelling the decision-making process for identification of optimal design concept from a set of alternatives can be modelled as an MCDA by hybridizing different MADM models. Hybridizing the fuzzy synthetic extent analysis of the FAHP model and fuzzifying the conventional Pugh matrix using all the alternatives as a basis has been able to identify a design concept as the optimal design. The method is suitable for decision making in conceptual engineering design because the final values of the design concepts representing the weights of their performance are moderately different. This indicates that the comparison was done based on the relative availability of the design features and sub-features in the design concepts and also based on a comparison among the design concepts. Also, the idea of determining the weights of design features and sub-features from pairwise comparison matrices limits the possibility of having bias judgement from decision-makers or design engineers. This is possible because the fuzzy pairwise comparison matrix is built based on the relative importance of the design features in the optimal design and contributions of the sub-features to the performance of the main design features.

\section{Acknowledgement}

The authors would like to thank the anonymous referees for constructive comments on earlier version of this paper.

\section{References}

Aikhuele, D. (2017). Interval-valued intuitionistic fuzzy multi-criteria model for design concept selection. Management Science Letters, 7(9), 457-466.

Akay, D., Kulak, O., \& Henson, B. (2011). Conceptual design evaluation using interval type-2 fuzzy information axiom. Computers in Industry, 62(2), 138-146.

Alarcin, F., Balin, A., \& Demirel, H. (2014). Fuzzy AHP and Fuzzy TOPSIS integrated hybrid method for auxiliary systems of ship main engines. Journal of Marine Engineering \& Technology, 13(1), 311.

Arjun Raj, A. S., \& Vinodh, S. (2016). A case study on application of ORESTE for agile concept selection. Journal of Engineering, Design and Technology, 14(4), 781-801.

Baležentis, T., \& Baležentis, A. (2014). A survey on development and applications of the multi-criteria decision making method MULTIMOORA. Journal of Multi-Criteria Decision Analysis, 21(3-4), 209-222.

Balin, A., Demirel, H., \& Alarcin, F. (2016). A novel hybrid MCDM model based on fuzzy AHP and fuzzy TOPSIS for the most affected gas turbine component selection by the failures. Journal of Marine Engineering \& Technology, 15(2), 69-78.

Chakraborty, K., Mondal, S., \& Mukherjee, K. (2017). Analysis of product design characteristics for remanufacturing using Fuzzy AHP and Axiomatic Design. Journal of Engineering Design, 28(5), 338-368.

Derelöv, M. (2009). On Evaluation of Design Concepts: Modelling Approaches for Enhancing the Understanding of Design Solutions (Doctoral dissertation, Linköping University Electronic Press).

Girod, M., Elliott, A. C., Burns, N. D., \& Wright, I. C. (2003). Decision making in conceptual engineering design: an empirical investigation. Proceedings of the Institution of Mechanical Engineers, Part B: Journal of Engineering Manufacture, 217(9), 1215-1228.

Green, G., \& Mamtani, G. (2004). An integrated decision making model for evaluation of concept design. Acta Polytechnica, 44(3).

Hambali, A., Sapuan, S. M., Ismail, N., \& Nukman, Y. (2009). Application of analytical hierarchy process in the design concept selection of automotive composite bumper beam during the conceptual design stage. Scientific Research and Essays, 4(4), 198-211. 
Hambali, A., Sapuan, S. M., Rahim, A. S., Ismail, N., \& Nukman, Y. (2011). Concurrent decisions on design concept and material using analytical hierarchy process at the conceptual design stage. Concurrent Engineering, 19(2), 111-121.

Muller, G. (2009). Concept selection: theory and practice. White paper of SESG meeting. sl: Buskerud University College.

Muller, G., D. Klever, H. H. Bjørnsen \& M. Pennotti (2011). Researching the application of Pugh Matrix in the sub-sea equipment industry by. CSER.

Nieto-Morote, A., \& Ruz-Vila, F. (2011). A fuzzy AHP multi-criteria decision-making approach applied to combined cooling, heating, and power production systems. International Journal of Information Technology \& Decision Making, 10(03), 497-517.

Okudan, G. E. \& R. A. Shirwaiker (2006). A multi-stage problem formulation for concept selection for improved product design. 2006 Technology Management for the Global Future-PICMET 2006 Conference, IEEE.

Okudan, G. E., \& Tauhid, S. (2008). Concept selection methods-a literature review from 1980 to 2008. International Journal of Design Engineering, 1(3), 243-277.

Olabanji, O. M. (2018). Reconnoitering the suitability of fuzzified weighted decision matrix for design process of a reconfigurable assembly fixture. International Journal of Design Engineering, 8(1), 3856.

Olabanji, O. M., \& Mpofu, K. (2014). Comparison of weighted decision matrix, and analytical hierarchy process for CAD design of reconfigurable assembly fixture. Procedia CIRP, 23, 264-269.

Renzi, C., Leali, F., \& Di Angelo, L. (2017). A review on decision-making methods in engineering design for the automotive industry. Journal of Engineering Design, 28(2), 118-143.

Renzi, C., Leali, F., Pellicciari, M., Andrisano, A. O., \& Berselli, G. (2015). Selecting alternatives in the conceptual design phase: an application of Fuzzy-AHP and Pugh's Controlled Convergence. International Journal on Interactive Design and Manufacturing (IJIDeM), 9(1), 117.

Sa'Ed, M. S., \& Al-Harris, M. Y. (2014). New product concept selection: an integrated approach using data envelopment analysis (DEA) and conjoint analysis (CA). International Journal of Engineering \& Technology, 3(1), 44.

Saridakis, K. M., \& Dentsoras, A. J. (2008). Soft computing in engineering design-A review. Advanced Engineering Informatics, 22(2), 202-221.

Singh, P. (2015). A Novel Method for Ranking Generalized Fuzzy Numbers. Journal of Information Science Engineering, 31(4), 1373-1385..

Somsuk, N., \& Simcharoen, C. (2011). A fuzzy AHP approach to prioritization of critical success factors for six sigma implementation: Evidence from the electronics industry in thailand. International Journal of Modeling and Optimization, 1(5), 432-437.

Thorani, Y. L. P., Rao, P. P. B., \& Shankar, N. R. (2012). Ordering generalized trapezoidal fuzzy numbers using orthocentre of centroids. International Journal of Algebra, 6(22), 1069-1085.

Tian, J., \& Yan, Z. F. (2013). Fuzzy analytic hierarchy process for risk assessment to generalassembling of satellite. Journal of applied research and technology, 11(4), 568-577.

Toh, C. A., \& Miller, S. R. (2015). How engineering teams select design concepts: A view through the lens of creativity. Design Studies, 38, 111-138.

Velu, L. G. N., Selvaraj, J., \& Ponnialagan, D. (2017). A new ranking principle for ordering trapezoidal intuitionistic fuzzy numbers. Complexity, 2017.

Zamani, S., Farughi, H., \& Soolaki, M. (2014). Contractor selection using fuzzy hybrid AHPVIKOR. International Journal of Research in Industrial Engineering, 2(4), 26-40. 


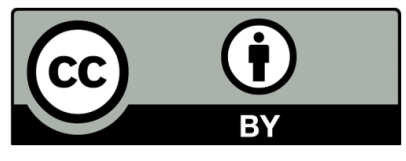

(C) 2020 by the authors; licensee Growing Science, Canada. This is an open access article distributed under the terms and conditions of the Creative Commons Attribution (CC-BY) license (http://creativecommons.org/licenses/by/4.0/). 